\title{
Maximal exercise in obese patients with COPD: the role of fat free mass
}

\author{
Marina Aiello, Elisabetta Teopompi, Panagiota Tzani, Sara Ramponi, Maria Rosaria Gioia, Emilio Marangio \\ and Alfredo Chetta*
}

\begin{abstract}
Background: Obese patients (OB) with COPD may better tolerate exercise as compared to normal weight (NW) COPD patients, even if the reason for this is not yet fully understood. We investigated the interactions between obesity, lung hyperinflation, fat-free mass (FFM) and exercise capacity in COPD.

Methods: Forty-four patients ( 16 females; age $65 \pm 8$ yrs) were assessed by resting lung function and body composition and exercised on a cycle-ergometer to exhaustion.

Results: Twenty-two OB and 22 NW patients did not differ in age, gender and airflow obstruction degree, but in FFM $(p<0.05)$. OB had significantly higher values in inspiratory capacity/total lung capacity ratio (IC/TLC) at rest $(p<0.01)$, but not at peak of exercise and showed significantly higher values in peak workload $(p<0.05)$ and in peak oxygen uptake $\left(\mathrm{VO}_{2}\right)$, when expressed as absolute value $(p<0.05)$, but not when corrected by FFM. OB compared to NW experienced lower leg fatigue $(p<0.05)$, but similar dyspnea on exertion. In all patients, the regression equation by stepwise multiple regression analysis for peak workload and $\mathrm{VO}_{2}$, as dependent variables included both FFM and IC/TLC at rest, as independent variables $\left(r^{2}=0.43\right.$ and 0.37 , respectively).

Conclusions: OB with COPD, as compared to NW patients matched for age, gender and airflow obstruction, had greater FFM and less resting lung hyperinflation and showed greater maximal exercise capacity. Pulmonary and non-pulmonary factors may explain the preservation of exercise tolerance in patients with COPD associated with obesity.
\end{abstract}

Keywords: Fat-free mass, Dynamic hyperinflation, Exercise, Obesity, COPD

\section{Background}

Obesity, an independent risk factor for reduced survival [1], is a frequent co-morbidity in patients with chronic obstructive pulmonary disease (COPD) [2]. Surprisingly, epidemiological studies have shown that overweight or mild-to-moderate obese patients with COPD have a survival advantage compared to underweight patients $[3,4]$, even if the reason for this is not yet clear [5]. It is also of note that, despite the increase in metabolic and ventilatory requirements, obesity also has the potential for significant beneficial effects on exercise tolerance in COPD [6].

\footnotetext{
*Correspondence: chetta@unipr.it

Dept of Clinical \& Experimental Medicine, Respiratory Disease and Lung Function Unit, University of Parma, Strada dell'Università 12, Parma 43100, Italy
}

\section{Biomed Central}

The impact of obesity on exercise capacity is not completely understood. Previous studies have shown that the combined mechanical effects of obesity and COPD may reduce operating lung volumes at rest and during exercise with favourable influences on breathlessness perception and peak oxygen uptake $[7,8]$. On the other hand, in COPD patients the decreased physical activity does not seem to depend merely on resting lung function and other factors are considered important in contributing to stagnation. Fat free mass (FFM) depletion commonly occurs in COPD patients and results from several factors, such as systemic inflammatory mediators, disuse atrophy, poor nutrition and oral corticosteroid medication [9]. The reduction in FFM may further significantly contribute to the impairment of exercise capacity in these patients. Previous studies have reported a significant correlation between FFM and maximal [10] and sub- 
maximal [11] exercise capacity in COPD patients. Furthermore, the depletion of lean body mass can reduce exercise capacity independently from ventilatory constraints during exertion [12].

Interestingly, in obese subjects, FFM may be increased $[13,14]$ as adaptation to the sustained loading effect from excessive adipose tissue. Therefore, we hypothesized that even in obese patients with COPD, an increase in FFM may occur with favourable effects on exercise capacity. In order to verify this hypothesis, we measured FFM in a group of obese patients with diagnosis of COPD and in a control group of normal weight COPD patients matched for age, gender and airflow obstruction. Then, we compared their cardiovascular and ventilatory response to incremental maximal exercise testing.

\section{Methods}

\section{Patients}

We consecutively enrolled patients affected by COPD, who were admitted to a pulmonary rehabilitation program. All patients underwent routine blood and urine analysis as an initial screening prior to the rehabilitation program. COPD was diagnosed according to the GOLD criteria [15] and patients with moderate to severe airflow obstruction, i.e., Forced Expiratory Volume in $1^{\text {st }}$ Second/Vital Capacity ratio $\left(\mathrm{FEV}_{1} / \mathrm{VC}\right)<70 \%$ and $\mathrm{FEV}_{1} \leq 80 \%$ of predicted value, were included. Eligibility criteria were: 1) stable clinical condition (exacerbation free for at least 4 weeks); 2) no oxygen therapy; 3) absence of any comorbidity affecting exercise performance (anaemia, neuromuscular disorders, chronic cardiac failure, malignancies); 4) ability to perform a symptomlimited cycle ergometry cardio pulmonary test (CPET) with a peak of respiratory exchange ratio (RER) $\geq 1.05$ in order to exclude poor motivation; 5) CPET stopped for muscle fatigue and/or dyspnoea.

All the procedures and their risks were explained to the patients, who gave their written informed consent to enter the study. The protocol was approved by the ethical committee of the University Hospital of Parma. All participants' data were analysed and reported anonymously.

\section{Lung function}

Pulmonary function tests were performed according to international recommendations [16,17]. A flow-sensing spirometer and a body plethysmograph connected to a computer for data analysis (Vmax 22 and 6200, Sensor Medics, Yorba Linda, U.S.A.) were used for the measurements. Vital Capacity (VC), Forced Expiratory Volume at $1^{\text {st }}$ Second $\left(\mathrm{FEV}_{1}\right)$, Forced Expiratory Flow measured at $50 \%$ of Forced Vital Capacity (FVC) $\left(\mathrm{FEF}_{50}\right.$ in L/s) and Forced Inspiratory Flow measured at $50 \%$ of $\mathrm{FVC}\left(\mathrm{FIF}_{50}\right.$ in $\left.\mathrm{L} / \mathrm{s}\right)$ were recorded. $\mathrm{FEV}_{1} / \mathrm{VC}$ and $\mathrm{FEF}_{50} / \mathrm{FIF}_{50}$ ratios were taken as indices of airway obstruction and airway collapsibility, respectively.
Functional Residual Capacity (FRC) was measured by body plethysmography with the subject panting against a closed shutter at a frequency slightly lower than $1 \mathrm{~Hz}$ whilst supporting their cheeks with their hands. Total Lung Capacity (TLC) was obtained as the sum of FRC and linked Inspiratory Capacity (IC). Residual Volume (RV) was obtained by subtracting VC from TLC. IC/TLC ratio was taken as an index of hyperinflation of the lung. At least three measurements were taken for each spirometry and lung volume variable to ensure reproducibility and the highest value obtained was used in subsequent calculations. The flow-sensor was calibrated before each test using a three-litre syringe.

Lung diffusion capacity for carbon monoxide (TLCo) was measured by the single breath method using a mixture of carbon monoxide and methane; this measurement was done at least in duplicate. TLC, VC, IC, FEV 1 and TLco were expressed as a percentage of the predicted values, which were obtained from regression equations by Quanjer et al. [18] and Cotes et al. [19].

\section{Cardiopulmonary exercise test}

CPET was performed prior to the rehabilitation program according to a standardized procedure [20]. After calibrating the oxygen and carbon dioxide analyzers and flow mass sensor, patients were asked to sit on an electromagnetically braked cycle ergometer (Corival PB, Lobe Bv, Groningen, The Netherlands) and the saddle was adjusted properly to avoid maximal extension of the knee. The exercise protocol involved an initial 3 minutes of rest, followed by unloaded cycling for another 3 minutes with an increment every minute of 5 to $15 \mathrm{~W}$ according to the patient's anthropometry and degree of functional impairment, in order to achieve an exercise time between 8-12 min. Patients were asked to maintain a pedalling frequency of $60 \mathrm{rpm}$ indicated by a digital display placed on the monitor of the ergometer. Breath-by-breath oxygen uptake $\left(\mathrm{VO}_{2}\right.$ in $\left.\mathrm{L} / \mathrm{min}\right)$, carbon dioxide production $\left(\mathrm{VCO}_{2}\right.$ in $\mathrm{L} / \mathrm{min})$, tidal volume $\left(\mathrm{V}_{\mathrm{T}}\right.$ in $\left.\mathrm{L}\right)$ and minute ventilation (VE in $\mathrm{L} / \mathrm{min}$ ) were recorded during the test (CPX/D; Med Graphics, St Paul, MN, U.S.A.). Patients were continuously monitored with a 12-lead electrocardiogram (Welch Allyn CardioPerfect, Delft, the Nederlands) and a pulse oximeter (Pulse Oximeter 8600, Nonin Medical Inc, MPLS, Mn U.S.A.). Blood pressure was measured at 2 minute intervals. Stopping criteria consisted of symptoms such as unsustainable dyspnoea or leg fatigue, chest pain, ECG significant ST-segment depression, a drop in systolic blood pressure or oxygen saturation $\left(\mathrm{SpO}_{2}\right) \leq 84 \%$.

Peak workload and peak $\mathrm{VO}_{2}$ were recorded as the mean value of watts and $\mathrm{VO}_{2}$ during the last 20 seconds of the test. Peak $\mathrm{VO}_{2}$ was expressed as absolute value in $\mathrm{mL} / \mathrm{min}$. Anaerobic threshold (AT) was non-invasively determined by both $\mathrm{V}$-slope and ventilatory equivalents 
methods ("dual method approach"), as the respiratory exchange ratio approximated 1.0 [20], and was expressed as absolute value in $\mathrm{mL} / \mathrm{min}$. Oxygen pulse $\left(\mathrm{O}_{2} \mathrm{Pulse}\right.$, in $\mathrm{mL} / \mathrm{bpm}$ ) was calculated by dividing instantaneous oxygen uptake by heart rate [20] and was recorded at rest and at peak of exercise.

Changes in operational lung volumes were assessed every two minutes during exercise and at peak of exercise, taking the IC measured at rest as the baseline. After a full explanation of the procedure to each patient, satisfactory technique and reproducibility of IC manoeuvres were established during an initial practice session at rest. Assuming that TLC remains constant during exercise in COPD [21], changes in IC reflect changes in endexpiratory lung volume (EELV). The end-tidal pressure of $\mathrm{CO}_{2}\left(\mathrm{PETCO}_{2}\right.$, in $\left.\mathrm{mm} \mathrm{Hg}\right)$ was measured as the mean of $\mathrm{PETCO}_{2}$ during the 3-minute rest period and during the last 20 seconds of the test and the difference between $\mathrm{PETCO}_{2}$ peak and $\mathrm{PETCO}_{2}$ rest $\left(\mathrm{PETCO}_{2}\right.$ peak-rest $)$ was recorded.

\section{Dyspnoea and muscle fatigue}

Daily living activity-related dyspnoea was evaluated with the Italian version of the five-point MRC scale modified by the ATS [22]. At the end of CPET patients were asked to name the predominant symptom limiting exercise. Dyspnoea and muscle fatigue induced by CPET were also measured at the end of incremental exercise by a visual analogue scale (VAS). The VAS scale consisted of a 100 -mm horizontal line with the word "none" placed at the left end of the scale and the word "very severe" placed at the right end of the scale. The VAS scored from 0 to 100 , but the subjects were unaware of the numbers. Dyspnoea and muscle fatigue ratings were then divided by the maximal workload $\left(\mathrm{VAS}_{\text {dys }}\right.$ and $\mathrm{VAS}_{\text {fat }}$, respectively in $\mathrm{mm} /$ watts) [23].

\section{Body composition}

Body height and weight were measured anthropometrically and body mass index (BMI, $\mathrm{kg} / \mathrm{m}^{2}$ ) was calculated in all patients. Body composition was assessed by a bioelectrical impedance analysis (BIA) method, which is based on the conductance of an electrical sinusoidal alternating current through body fluids. BIA measures the impedance or resistance to the signal as it travels through the water that is found in muscle and fat. Foot-to-foot BIA was measured using a SC-331S Body Composition analyzer (TANITA CO., Tokyo, Japan). Patients were measured in a standing position with bare feet on the analyzer footpads. The algorithms used to estimate lean body mass from impedance are those given by Segal et al. [24]. Fat mass (FM) and FFM were measured in all patients. FFM was also standardized for height similar to BMI: FFM index (FFMI: FFM/height ${ }^{2}, \mathrm{~kg} / \mathrm{m}^{2}$ ).

\section{Statistical analysis}

This is a cross-sectional pilot study. Due to the explorative nature of the study no formal sample size calculation was performed. Data are reported as mean \pm standard deviation (SD), unless otherwise specified. The distribution of variables was assessed by means of the KolmogorovSmirnov Goodness-of-Fit test. Relationships between variables were assessed by the Pearson's correlation coefficient $(r)$ and linear regression analysis. Comparisons between variables were determined by unpaired $t$ test and $\chi^{2}$ test, when appropriate. Stepwise multiple regression analysis was used to determine the best predictor variables for peak workload and $\mathrm{VO}_{2}$ as dependent variables. Percentage of total variance in the dependent variable, accounted for by the predictor variables, is expressed as the adjusted square of the multiple correlation coefficient $\left(r^{2}\right)$.

According to the BMI value [25], population sample was divided into normal weight (NW, BMI $18.5-24.9 \mathrm{~kg} / \mathrm{m}^{2}$ ) and obese $\left(\mathrm{OB}, \mathrm{BMI} \geq 30 \mathrm{~kg} / \mathrm{m}^{2}\right)$ patients. According to IC/TLC, patients of both groups were also divided in two categories: patients with IC/TLC $\leq 0.25$ or $>0.25$ both at rest and at peak of exercise. In COPD a IC/TLC ratio > 0.25 at rest is an established favourable prognostic indicator [26] and at peak is associated to less negative cardiovascular effects [27].

A $p$ value of less than 0.05 was taken as significant.

\section{Results}

Sixty consecutive stable COPD patients (19 females), aged between 42 and 75 years were screened. All of them were ex-smokers. Sixteen patients were excluded because of their BMI $\left(<19, \geq 25\right.$ or $\left.<30 \mathrm{~kg} / \mathrm{m}^{2}\right)$. Twenty-two NW patients (BMI range: $19.0-24.9 \mathrm{~kg} / \mathrm{m}^{2}$ ) and $22 \mathrm{OB}$ patients with COPD (BMI range: $30.1-44.8 \mathrm{~kg} / \mathrm{m}^{2}$ ) were studied. Twenty-nine ( 8 females) out of 44 patients $(66 \%)$ suffered from controlled arterial hypertension and were taking diuretics (38\%), Ca-antagonists (34\%), beta-blockers (34\%), and ACE-inhibitors (28\%). The prevalence of arterial hypertension was not different between $\mathrm{NW}$ and $\mathrm{OB}$ patients (64\% vs 68\%). Additionally, the percentage of patients on beta-blockers was not different.

Demographic and clinical characteristics of the 44 patients included in the study are shown in Table 1 . The two groups of patients differed in FM, FFM and FFMI values, but not in age, gender and airflow obstruction and airway collapsibility degree. OB patients showed lower values in TLC, VC and FRC when compared to NW patients (Figure 1). In all patients, BMI was negatively related to TLC $(r=-0.343 ; \mathrm{p}<0.05)$ and FRC $(\mathrm{r}=-0.394$; $\mathrm{p}<0.05)$ and positively to resting IC/TLC ratio $(\mathrm{r}=0.512$; $\mathrm{p}<0.001$ ).

All the included patients completed the exercise test without any complications. The work rate increments during the exercise were not different between $\mathrm{OB}$ and 
Table 1 Demographic and baseline characteristics of COPD patients

\begin{tabular}{|c|c|c|}
\hline & $\begin{array}{l}\text { Normal weight } \\
\qquad(n=22)\end{array}$ & $\begin{array}{l}\text { Obese } \\
(n=22)\end{array}$ \\
\hline Age (years) & $66 \pm 6$ & $66 \pm 6$ \\
\hline Females/Males & $9 / 13$ & $7 / 15$ \\
\hline BMI $\left(\mathrm{kg} / \mathrm{m}^{2}\right)$ & $22 \pm 2$ & $34 \pm 4^{* *}$ \\
\hline $\mathrm{FM}(\mathrm{kg})$ & $14.7 \pm 5.9$ & $36.2 \pm 10.4^{* *}$ \\
\hline FFM (kg) & $46.2 \pm 6.9$ & $55.2 \pm 8.8^{* *}$ \\
\hline FFMI $\left(\mathrm{kg} / \mathrm{m}^{2}\right)$ & $16.5 \pm 1.7$ & $19.8 \pm 2.3^{* *}$ \\
\hline MRC (0-4) & $1(0-4)$ & $1(0-4)$ \\
\hline TLC (\% pred) & $128 \pm 25$ & $102 \pm 22^{* *}$ \\
\hline VC (\% pred) & $89 \pm 17$ & $77 \pm 12^{* *}$ \\
\hline FRC (\% pred) & $161 \pm 34$ & $137 \pm 40^{*}$ \\
\hline RV (\% pred) & $187 \pm 45$ & $168 \pm 56$ \\
\hline $\mathrm{FEV}_{1}$ (\% pred) & $52 \pm 13$ & $50 \pm 12$ \\
\hline $\mathrm{FEV}_{1}$ NC (\%) & $50 \pm 11$ & $53 \pm 9$ \\
\hline $\mathrm{FEF}_{50} / \mathrm{FIF}_{50}$ & $0.32 \pm 0.23$ & $0.29 \pm 0.12$ \\
\hline $\mathrm{TL}_{\mathrm{CO}}(\%$ pred $)$ & $60 \pm 16$ & $78 \pm 18^{* *}$ \\
\hline
\end{tabular}

NW patients ( 8.9 watts \pm 2.9 vs 8.5 watts \pm 2.5 ). When patients were asked to name the predominant symptom limiting the exercise test, $13 \mathrm{OB}$ and $10 \mathrm{NW}$ named exertion dyspnea, $6 \mathrm{OB}$ and $8 \mathrm{NW}$ named leg fatigue, whereas $3 \mathrm{OB}$ and $4 \mathrm{NW}$ named both symptoms. Exercise data are summarized in Table 2. The two groups of patients significantly differed in terms of peak $\mathrm{VO}_{2}$ when expressed as absolute value $(\mathrm{p}<0.05)$ (Figure 2), but not when it was corrected by FFM and in terms of peak workload $(\mathrm{p}<0.05)$. An AT was detected in $17 \mathrm{NW}$ and in $19 \mathrm{OB}$ patients and $\mathrm{VO}_{2}$ at $\mathrm{AT}$ was significantly higher in the $\mathrm{OB}$ group than in the NB group $(1,145 \pm$ 388 vs $821 \pm 309 \mathrm{~mL} / \mathrm{min} ; \mathrm{p}<0.05)$. In addition, IC/TLC was significantly higher at rest $(\mathrm{p}<0.01)$, but not at peak of exercise in $\mathrm{OB}$ as compared to NW (Figure 2), being >

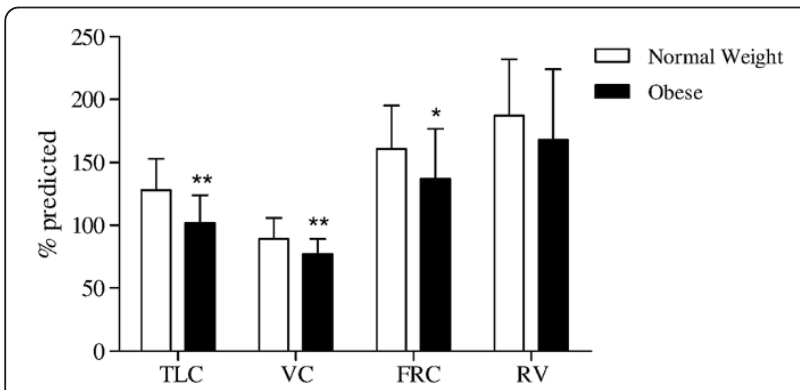

Figure 1 Mean and standard deviation values of TLC, VC, FRC and RV in 22 normal weight and in 22 obese patients with COPD. ${ }^{*} p<0.05,{ }^{* *} p<0.01$.
Table 2 Exercise characteristics of 22 normal weight (NW) and 22 obese (OB) patients with COPD

\begin{tabular}{|c|c|c|c|c|}
\hline & \multicolumn{2}{|c|}{ Rest } & \multicolumn{2}{|c|}{ Peak } \\
\hline & NW & OB & NW & OB \\
\hline$\overline{\mathrm{VO}_{2}(\mathrm{~mL} / \mathrm{min})}$ & $284 \pm 77$ & $313 \pm 81$ & $1,114 \pm 308$ & $1,405 \pm 482^{*}$ \\
\hline $\mathrm{VO}_{2} / \mathrm{FFM}(\mathrm{mL} / \mathrm{kg})$ & $6.3 \pm 2.0$ & $5.9 \pm 1.9$ & $24.1 \pm 5.7$ & $25.6 \pm 7.6$ \\
\hline Workload (watts) & 0 & 0 & $74 \pm 24$ & $94 \pm 36^{*}$ \\
\hline VE (L/min) & $11.5 \pm 2.2$ & $10.7 \pm 3.2$ & $42.1 \pm 13.1$ & $40.8 \pm 12.3$ \\
\hline $\mathrm{IC} / \mathrm{TLC}$ & $0.28 \pm 0.09$ & $0.36 \pm 0.08^{* *}$ & $0.25 \pm 0.08$ & $0.29 \pm 0.08$ \\
\hline $\mathrm{V}_{T} \mathrm{NC}$ & $0.23 \pm 0.08$ & $0.27 \pm 0.07$ & $0.42 \pm 0.15$ & $0.55 \pm 0.11^{* *}$ \\
\hline$V_{T} / I C$ & $0.36 \pm 0.12$ & $0.31 \pm 0.09$ & $0.73 \pm 0.33$ & $0.62 \pm 0.11$ \\
\hline $\mathrm{PETCO}_{2}(\mathrm{~mm} \mathrm{Hg})$ & $30 \pm 4$ & $36 \pm 3$ & $36 \pm 6$ & $44 \pm 7$ \\
\hline $\mathrm{SpO}_{2}(\%)$ & $96 \pm 2$ & $95 \pm 2$ & $95 \pm 2$ & $94 \pm 3$ \\
\hline HR (bpm) & $79 \pm 14$ & $84 \pm 13$ & $123 \pm 18$ & $124 \pm 18$ \\
\hline $\mathrm{O}_{2}$ Pulse (mL/bpm) & $3.6 \pm 1.0$ & $3.8 \pm 0.9$ & $9.2 \pm 2.9$ & $11.3 \pm 3.7^{*}$ \\
\hline $\begin{array}{l}\text { VAS dyspnea } \\
\text { (mm/watt) }\end{array}$ & 0 & 0 & $1.17 \pm 1.0$ & $1.12 \pm 0.9$ \\
\hline $\begin{array}{l}\text { VAS fatigue } \\
\text { (mm/watt) }\end{array}$ & 0 & 0 & $1.19 \pm 0.5$ & $0.89 \pm 0.4^{*}$ \\
\hline
\end{tabular}

${ }^{*} p$ value $<0.05$

${ }^{* *} p$ value $<0.01$

Values are expressed as mean $\pm \mathrm{SD}$.

0.25 at rest in 14 out of $22(64 \%) \mathrm{NW}$ and in 20 out of $22(91 \%)$ OB patients (chi square $=4.659 ; \mathrm{p}=0.031$ ) and $>0.25$ at peak in 9 out of $22(41 \%) \mathrm{NW}$ and in 11 out of $22(50 \%)$ OB patients (chi square $=0.0283$; $\mathrm{p}=0.866$ ). The two groups of patients differed both in $\mathrm{PETCO}_{2}$ rest and in $\mathrm{PETCO}_{2}$ peak values, which were significantly higher in $\mathrm{OB}$ patients than in NW patients $(\mathrm{p}<0.05)$, but not in $\mathrm{PETCO}_{2}$ peak-rest $(8 \pm 6$ vs $6 \pm$ $4 \mathrm{~mm} \mathrm{Hg} ; \mathrm{p}=0.218$ ). As compared to NW, OB experienced lower leg fatigue $(\mathrm{p}<0.05)$, but similar dyspnea on exertion.

The two groups of patients were not different in rest $\mathrm{O}_{2}$ Pulse values, but they significantly differed in peak $\mathrm{O}_{2}$ Pulse and in peak-rest $\mathrm{O}_{2}$ Pulse values $(7.6 \pm 3$ vs $5.6 \pm 3 \mathrm{~mL} / \mathrm{bpm}$ ), which were both significantly higher in OB patients than in NW patients $(\mathrm{p}<0.05)$ (Figure 2). In all patients, peak $\mathrm{O}_{2}$ Pulse and peak-rest $\mathrm{O}_{2}$ Pulse values were significantly and positively related to FFM $(r=0.496$, $\mathrm{p}<0.001$ and $\mathrm{r}=0.533, \mathrm{p}<0.001$ ).

Lastly, in all patients significant positive correlations were found between peak workload and FFM $(r=0.584$, $\mathrm{p}=0.001)$ and IC/TLC at rest $(\mathrm{r}=0.573, \mathrm{p}=0.001)$ and between $\mathrm{VO}_{2}$ and FFM $(\mathrm{r}=0.552, \mathrm{p}=0.001)$ and IC/TLC at rest $(\mathrm{r}=0.520, \mathrm{p}=0.001)$. Moreover, when all patients were categorized into two groups according to the median value of FFM (42 kg in females and $54 \mathrm{~kg}$ in males), patients with a FFM value higher than that of the median showed higher values in peak workload ( 99 watt \pm 36 vs 74 watt $\pm 25, \mathrm{p}<0.05)$, peak $\mathrm{VO}_{2}(1438 \mathrm{ml} / \mathrm{min} \pm 483$ vs 


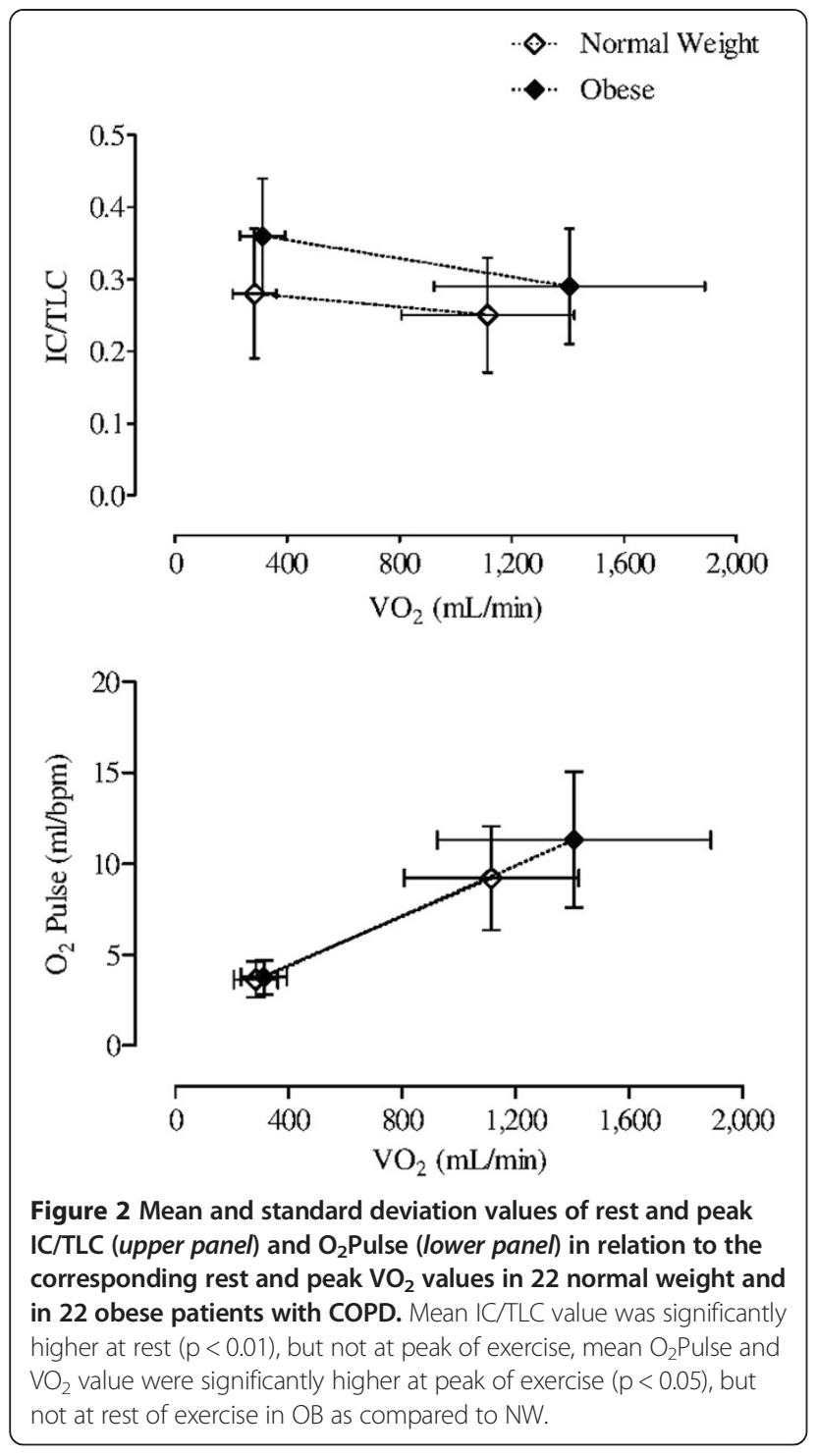

$1141 \mathrm{ml} / \mathrm{min} \pm 342 ; \mathrm{p}<0.05)$ and in IC/TLC at rest $(0.28 \pm$ 0.09 vs $0.39 \pm 0.07 ; \mathrm{p}<0.01)$. The regression equation generated by stepwise multiple regression analysis for peak workload and $\mathrm{VO}_{2}$, as dependent variables, included FFM and IC/TLC at rest. This model accounted for $43 \%$ and $37 \%$ of the total variance of the peak workload (in watts) and of $\mathrm{VO}_{2}$ (in $\mathrm{mL}$ ) respectively, according to the following regression equations: $\mathrm{W}=-26.46+1.39(\mathrm{FFM})+$ 126.85 (IC/TLC rest) and $\mathrm{VO}_{2}=-111.8+18.2($ FFM $)+$ 1436.1 (IC/TLC rest).

\section{Discussion}

The main finding of the present study is that obese patients with COPD, as compared to normal weight patients matched for age, gender and airflow obstruction, show greater fat-free mass and less lung hyperinflation at rest, as assessed by the IC/TLC ratio. When performing a maximal exercise test by cycling, obese patients compared to controls have greater exercise capacity both in terms of peak workload and in terms of oxygen uptake at peak, expressed as absolute value, but not when corrected for fat-free mass. In all patients, by means of multiple regression analysis fat-free mass and resting lung hyperinflation were found to be determining factors of the peak workload and oxygen uptake at peak. Lastly, as compared to controls obese patients experienced a comparable degree of dyspnoea and less leg fatigue on exertion.

Obesity may affect respiratory physiology both at rest and during exercise. Obese individuals show decreased respiratory system compliance, which results in a restrictive ventilatory defect. Low functional residual capacity and reductions in expiratory reserve volume increase the risk of expiratory flow limitation and airway closure during quiet breathing, especially in the supine position [28]. Moreover, in obese individuals, the increase of ventilation during exercise can further induce gas trapping and a rise of EELV [29]. Paradoxically, the dynamic increase in EELV may result in a mechanical advantage in obese subjects while exercising, since tidal volume shifts to the more compliant portion of the pressure-volume relation of the respiratory system [6]. The reduction in operating lung volumes during exercise may have favourable influences especially in obese patients with COPD, in whom obesity may counterbalance lung hyperinflation, thereby significantly improving their exercise tolerance $[7,8]$.

In the present study, as compared to normal weight patients with COPD, the COPD patients with combined obesity developed during exercise, as assessed by the IC/ TLC ratio at peak of exercise, dynamic hyperinflation of comparable magnitude and a similar degree of ventilatory limitation, as assessed by the difference in peak-rest $\mathrm{PETCO}_{2}$ value. Despite this, obese patients showed greater maximal exercise capacity both in terms of peak workload and in terms of oxygen uptake, thanks to their better starting conditions consisting in less lung hyperinflation at rest. Our results confirm and extend those of previous reports $[7,8]$. In this study, we also provided the first evidence that obese COPD patients, compared to normal weight COPD patients had a greater amount of lean body mass, which together with lung hyperinflation was a determinant factor of maximal exercise capacity in all patients. Therefore, both pulmonary and non-pulmonary factors may explain the preservation of exercise tolerance in patients with combined COPD and obesity.

It is not surprising to find a greater amount of fat-free mass in obese patients in comparison to normal weight controls, since the increase in fat-free mass represents an adaptation to the sustained loading effect from excessive adipose tissue. Previously, Babb et al. [13] by investigating the relationship between EELV, body composition 
and fat distribution in a group of lean and obese young adult men and women, incidentally reported that the lean mass was increased in obese subjects by $10 \mathrm{~kg}$, both in men and in women. Similarly, Wood et al. [14] studying the aerobic power in overweight and obese young adults, reported a significant increase of fat-free mass in obese subjects. The greater amount of lean body mass in obese COPD patients could be an explanation of the seemingly counterintuitive paradox of obesity, which from a risk factor results in a survival advantage of chronic disease states or conditions associated with wasting disease at the population level [5].

Lean body mass may have favourable effects on exercise tolerance in patients with wasting diseases, such as COPD [30]. Notably, the skeletal muscle pump has local and systemic circulatory effects, since it may enhance venous return, central venous pressure, end-diastolic volume, and thus stroke volume and cardiac output, by expulsing the peripheral venous blood volume during exercise [31]. It is of note that in this study we found that in comparison to controls, obese patients showed a better cardiovascular response to exercise, expressed as oxygen pulse, which can be considered as a reliable surrogate marker of the stroke volume [32]. In addition, oxygen pulse was strictly related to FFM in all COPD patients.

This study has some limitations. Firstly, our obese patients showed mild-to-moderate obesity and our results cannot be generalizable to all obese patients, including those with morbid obesity. Secondly, in our study patients experienced maximal exercise capacity by using cycle ergometry, therefore, our results cannot be applicable to other forms of exercise, such as running on a treadmill, where the metabolic load is greater. Thirdly, in our patients body composition was assessed by bioelectrical impedance analysis, which is sensitive to the hydration status of the subject whereas, distribution of body fat was not analysed. However, our patients showed normal hydration status, as assessed by means of urinalysis, including urine specific gravity. Moreover, in both men and women with obesity the decrease in endexpiratory lung volume appears to be related to the cumulative effect of increased chest wall fat rather than to any specific regional chest wall fat distribution [13]. Lastly, our study is a cross-sectional study, therefore, on the basis of our results we can only infer and not establish the contributors of exercise tolerance in obese patients with COPD. Thus, a further longitudinal study on exercise tolerance in obese patients, who change their weight and body composition over time, is needed.

\section{Conclusions}

OB with COPD, as compared to NW patients matched for age, gender and airflow obstruction, had greater FFM and less resting lung hyperinflation and showed greater maximal exercise capacity. Pulmonary and non-pulmonary factors may explain the preservation of exercise tolerance in patients with COPD associated with obesity.

\begin{abstract}
Abbreviations
AT: Anaerobic threshold; BMI: Body mass index; COPD: Chronic obstructive pulmonary disease; CPET: Cardiopulmonary exercise test; $\mathrm{FEF}_{50}$ : Forced expiratory flow measured at $50 \%$ of FVC; FEV 1 : Forced expiratory volume in the $1^{\text {st }}$ second; FIF $_{50}$ : Forced inspiratory flow measured at $50 \%$ of FVC.; FFM: Fat-free mass; FFMI: Fat-free mass index; FM: Fat mass; FRC: Functional residual capacity; FVC: Forced vital capacity; HR: Heart rate; IC: Inspiratory capacity; $\mathrm{O}_{2}$ Pulse: Oxygen pulse; RV: Residual volume; SD: Standard deviation; TLC: Total lung capacity; TLco: Lung diffusion capacity for carbon monoxide; VAS: Visual analogue scale; VC: Vital capacity; $\mathrm{VCO}_{2}$ : Carbon dioxide production; VE: Minute ventilation; $\mathrm{VO}_{2}$ : Oxygen uptake; $\mathrm{V}_{T}$ : Tidal volume.
\end{abstract}

\section{Competing interests}

The authors declare that they have no competing interests.

\section{Authors' contributions}

MA served as the primary author. She developed the study protocol, participated in the patient recruitment and statistical analysis and drafted the manuscript and she is the guarantor of the entire manuscript. PT, SR, ET and MRG participated in the design of the study and helped with patient recruitment. EM participated in the coordination of the study. AC developed the study protocol, interpreted study data, contributed to and reviewed drafts of the manuscript. All authors read and approved the final manuscript.

\section{Acknowledgements}

The authors gratefully acknowledge the patients who volunteered for this study and Ms. Maria Pia Salati, Lung Function Unit of the University Hospital of Parma, for performing pulmonary function testing. No extramural funding was used to support the study.

Received: 27 February 2014 Accepted: 21 May 2014

Published: 30 May 2014

\section{References}

1. Adams KF, Schatzkin A, Harris TB, Kipnis V, Mouw T, Ballard-Barbash R, Hollenbeck A, Leitzmann MF: Overweight, obesity, and mortality in a large prospective cohort of persons 50 to 71 years old. N Engl J Med 2006, 355:763-778.

2. Franssen FM, O'Donnell DE, Goossens GH, Blaak EE, Schols AM: Obesity and the lung: 5. Obesity and COPD. Thorax 2008, 63:1110-1117.

3. Wilson DO, Rogers RM, Wright EC, Anthonisen NR: Body weight in chronic obstructive pulmonary disease. The national institutes of health intermittent positive-pressure breathing trial. Am Rev Respir Dis 1989, 139:1435-1438.

4. Landbo C, Prescott E, Lange P, Vestbo J, Almdal TP: Prognostic value of nutritional status in chronic obstructive pulmonary disease. Am J Respir Crit Care Med 1999, 160:1856-1861.

5. Kalantar-Zadeh K, Horwich TB, Oreopoulos A, Kovesdy CP, Younessi H, Anker SD, Morley JE: Risk factor paradox in wasting diseases. Curr Opin Clin Nutr Metab Care 2007, 10:433-442.

6. O'Donnell DE, O'Donnell CD, Webb KA, Guenette JA: Respiratory consequences of mild-to-moderate obesity: impact on exercise performance in health and in chronic obstructive pulmonary disease. Pulm Med 2012, 2012:818925.

7. Ora J, Laveneziana P, Ofir D, Deesomchok A, Webb KA, O'Donnell DE: Combined effects of obesity and chronic obstructive pulmonary disease on dyspnea and exercise tolerance. Am J Respir Crit Care Med 2009, 180:964-971.

8. Ora J, Laveneziana P, Wadell K, Preston M, Webb KA, O'Donnell DE: Effect of obesity on respiratory mechanics during rest and exercise in COPD. J Appl Physiol 2011, 111:10-19.

9. Kim HC, Mofarrahi M, Hussain SNA: Skeletal muscle dysfunction in patients with chronic obstructive pulmonary disease. Int J Chron Obstruct Pulmon Dis 2008, 3:637-658. 
10. Baarends EM, Schols AMWJ, Mostert R, Wouters EFM: Peak exercise response in relation to tissue depletion in patients with chronic obstructive pulmonary disease. Eur Respir J 1997, 10:2807-2813.

11. Schols AM, Mostert R, Soeters PB, Wouters EF: Body composition and exercise performance in patients with chronic obstructive pulmonary disease. Thorax 1991, 46:695-699.

12. Teopompi E, Tzani P, Aiello M, Ramponi S, Andrani F, Marangio E, Clini E, Chetta A: Fat free mass depletion is associated to poor exercise capacity irrespective of dynamic hyperinflation in COPD patients. Respir Care 2014, 59:718-725.

13. Babb TG, Wyrick BL, DeLorey DS, Chase PJ, Feng MY: Fat distribution and end-expiratory lung volume in lean and obese men and women. Chest 2008, 134:704-711.

14. Wood RE, Hills AP, Hunter GR, King NA, Byrne NM: VO $\mathrm{V}_{2 \max }$ in overweight and obese adults: do they meet the threshold criteria? Med Sci Sports Exerc 2010, 423:470-477.

15. Pauwels RA, Buist AS, Calverley PM, Jenkins CR, Hurd SS, GOLD Scientific Committee: Global strategy for the diagnosis, management, and prevention of chronic obstructive pulmonary disease. NHLBI/WHO global initiative for chronic obstructive lung disease (GOLD) workshop summary. Am J Respir Crit Care Med 2001, 163:1256-1276.

16. Miller MR, Hankinson J, Brusasco V, Burgos F, Casaburi R, Coates A, Crapo R, Enright P, Van der Grinten CP, Gustafsson P, Jensen R, Johnson DC, MacIntyre N, McKay R, Navajas D, Pedersen OF, Pellegrino R, Viegi G, Wanger J, ATS/ERS Task Force: Standardisation of spirometry. Eur Respir J 2005, 26:319-338.

17. Wanger J, Clausen JL, Coates A, Pedersen OF, Brusasco V, Burgos F, Casaburi R, Crapo R, Enright P, Van der Grinten CP, Gustafsson P, Hankinson J, Jensen $R$, Johnson D, Macintyre N, McKay R, Miller MR, Navajas D, Pellegrino R, Viegi G: Standardisation of the measurement of lung volumes. Eur Respir J 2005, 26:511-522.

18. Quanjer PH, Tammeling GJ, Cotes JE, Pedersen OF, Peslin R, Yernault JC: Lung volumes and forced ventilatory flows. Report working party standardization of lung function tests, European community for steel and coal. official statement of the European respiratory society. Eur Respir J 1993, 6(Suppl):5-40.

19. Cotes JE, Chinn DJ, Quanjer PH, Roca J, Yernault JC: Standardization of the measurement of transfer factor (diffusing capacity). Report working party standardization of lung function tests, European community for steel and coal. official statement of the European respiratory society. Eur Respir J 1993, 6(Suppl):41-52.

20. ATS/ACCP: Statement on cardiopulmonary exercise testing. Am J Respir Crit Care Med 2003, 167:211-277.

21. Stubbing DG, Pengelly LD, Morse $\mathrm{J}$, Jones NL: Pulmonary mechanics during exercise in subjects with chronic airflow obstruction. J Appl Physiol 1980, 49:511-515.

22. Brooks SM: Surveillance for respiratory hazards. ATS News 1982, 8:12-16.

23. Tzani P, Piepoli MF, Longo F, Aiello M, Serra W, Maurizio AR, Olivieri D, Chetta A: Resting lung function in the assessment of the exercise capacity in patients with chronic heart failure. Am J Med Sci 2010, 339:210-215.

24. Segal KR, Van Loan M, Fitzgerald PI, Hogdon JA, Van Itallie TB: Lean body mass estimation by bioelectrical impedance analysis: a four-site cross-validation study. Am J Clin Nutr 1988, 47:7-14.

25. Kopelman PG: Obesity as a medical problem. Nature 2000, 404:635-643.

26. Casanova C, Cote C, De Torres JP, Aguirre-Jaime A, Marin JM, Pinto-Plata V, Celli BR: Inspiratory-to-total lung capacity ratio predicts mortality in patients with chronic obstructive pulmonary disease. Am J Respir Crit Care Med 2005, 171:591-597.

27. Tzani P, Aiello M, Elia D, Boracchia L, Marangio E, Olivieri D, Clini E, Chetta A: Dynamic Hyperinflation is Associated with a Poor Cardiovascular Response to Exercise in COPD Patients. Respir Res 2011, 12:150.

28. Lin C-K, Lin C-C: Work of breathing and respiratory drive in obesity. Respirology 2012, 17:402-411.

29. Ofir D, Laveneziana P, Webb KA, O'Donnell DE: Ventilatory and perceptual responses to cycle exercise in obese women. J Appl Physiol 2007, 102:2217-2226.
30. Visca D, Aiello $M$, Chetta A: Cardiovascular function in pulmonary emphysema. Biomed Res Int 2013, 2013:184678.

31. Sheriff D: Point: the muscle pump raises muscle blood flow during locomotion. J Appl Physiol 2005, 99:371-372.

32. Whipp BJ, Higgenbotham MB, Cobb FC: Estimating exercise stroke volume from asymptotic oxygen pulse in humans. J Appl Physiol 1996, 81:2674-2679.

doi:10.1186/1471-2466-14-96

Cite this article as: Aiello et al.: Maximal exercise in obese patients with COPD: the role of fat free mass. BMC Pulmonary Medicine 2014 14:96.

\section{Submit your next manuscript to BioMed Central and take full advantage of:}

- Convenient online submission

- Thorough peer review

- No space constraints or color figure charges

- Immediate publication on acceptance

- Inclusion in PubMed, CAS, Scopus and Google Scholar

- Research which is freely available for redistribution

Submit your manuscript at www.biomedcentral.com/submit

C BioMed Central 